\title{
Photocatalytic Hydrogen Generation from a Visible-Light Responsive Metal- Organic Framework System: The Impact of Nickel Phosphide Nanoparticles
}

Stavroula Kampouri, ${ }^{a}$ Tu N. Nguyen, ${ }^{a}$ Christopher P. Ireland, ${ }^{a}$ Bardiya Valizadeh, ${ }^{a}$ Fatmah Mish Ebrahim, ${ }^{a}$ Gloria Capano, ${ }^{a}$ Daniele Ongari, ${ }^{a}$ Amber Mace, ${ }^{a b}$ Nestor Guijarro Carratala, ${ }^{c}$ Kevin Sivula, ${ }^{c}$ Andrzej Sienkiewicz, ${ }^{d}$ László Forró, ${ }^{d}$ Berend Smit, ${ }^{a}$ Kyriakos C. Stylianou ${ }^{a *}$

a. Institute of Chemical Sciences and Engineering (ISIC), Ecole Polytechnique Fédérale de Lausanne (EPFL Valais), Rue de l'industrie 17, 1951 Sion (Switzerland). E-mail: Kyriakos.stylianou@epfl.ch

b. Department of Materials and Environmental Chemistry, Arrhenius Laboratory Stockholm University.

c. Institute of Chemical Sciences and Engineering (ISIC), Ecole Polytechnique Fédérale de Lausanne (EPFL), Station 6, 1015 Lausanne (Switzerland).

d. Institute of Physics, Ecole Polytechnique Fédérale de Lausanne (EPFL), Station 3, 1015 Lausanne (Switzerland).

$\dagger$ Electronic Supplementary Information (ESI) available: Experimental methods, Synthetic procedures, characterization and computational details. This material is available free of charge via the internet at See DOI: 10.1039/x0xx00000x

\begin{abstract}
Herein, we report the performance of a photocatalytic system based on the visible-light active MIL-125- $\mathrm{NH}_{2}$ mixed with nickel phosphide $\left(\mathrm{Ni}_{2} \mathrm{P}\right)$ nanoparticles. This combination boosts the $\mathrm{H}_{2}$ evolution rate to an outstanding value of $894 \mu \mathrm{mol} \mathrm{h}^{-1} \mathrm{~g}^{-1}$ under visible-light irradiation, which is among the highest $\mathrm{H}_{2}$ evolution rates reported to date for metal-organic frameworks (MOFs). $\mathrm{The}_{2} \mathrm{H}_{2}$ generation rate produced by $\mathrm{Ni}_{2} \mathrm{P} / \mathrm{MIL}-125-\mathrm{NH}_{2}$ is almost 3 times higher than that of $\mathrm{Pt} / \mathrm{MIL}-125-\mathrm{NH}_{2}$ system, highlighting the impact of the co-catalyst in photocatalytic water splitting. Additionally, our system outperforms the $\mathrm{Ni}_{2} \mathrm{P} / \mathrm{TiO}_{2}$ system under UV-Vis irradiation. The exceptional performance of $\mathrm{Ni}_{2} \mathrm{P} / \mathrm{MIL}-125-\mathrm{NH}_{2}$ is due to the efficient transfer of photogenerated electrons from MIL-125- $\mathrm{NH}_{2}$ to $\mathrm{Ni}_{2} \mathrm{P}$, high intrinsic activity of $\mathrm{Ni}_{2} \mathrm{P}$ and exceptional synergy between them. This system exhibits the highest apparent quantum yields of 27.0 and 6.6 $\%$ at 400 and $450 \mathrm{~nm}$, respectively, ever reported for MOFs.
\end{abstract}

Hydrogen $\left(\mathrm{H}_{2}\right)$ gas is widely produced and used in industries, particularly in fossil fuel processing and ammonia synthesis. ${ }^{1}$ In addition, it is considered as a clean energy carrier for a sustainable energy future, since the combustion of $\mathrm{H}_{2}$ results in the generation of water and no greenhouse gasses, which eliminates the risk of climate change and allows for a carbon-neutral energy cycle. ${ }^{2}$ Traditional methods for $\mathrm{H}_{2}$ production include methane steam reforming and coal gasification; however, these processes also produce carbon dioxide as a by-product that needs to be captured and sequestered. ${ }^{3} \mathrm{H}_{2}$ can also be generated from water electrolysis using electricity but the electricity must also be obtained from a renewable energy source such as solar, wind, hydroelectric, or hydrothermal energy. A superior method to generate $\mathrm{H}_{2}$ is through artificial photosynthesis, which utilizes the inexhaustible solar energy to directly convert water into $\mathrm{H}_{2}{ }^{4}$ Owing to the sustainable nature of this procedure and the potential cost efficiency, many research efforts in materials science have been focused on developing novel photocatalytic systems that can enhance the rate of $\mathrm{H}_{2}$ evolution, with $10 \%$ quantum efficiencies being the lower limit for commercial applications to be feasible. ${ }^{5,6}$ However, due to the negligible absorptivity of traditional photocatalysts such as $\mathrm{TiO}_{2}$ and $\mathrm{SnO}_{2}$ toward the visible-light, the low water stability of other alternatives such as $\mathrm{CdS}$ or GaAs, and the high cost of noble metal co-catalysts, no photocatalytic systems have been industrially applied. ${ }^{7,8}$ 
A metal-organic framework (MOF) is a network of metal ions or clusters bridged by organic ligands through coordination bonds into a porous extended structure. ${ }^{9-11}$ MOFs offer the exciting possibility to integrate a light harvesting moiety (ligand), a catalytic component (reductive metal ions), and intrinsic porosity into a single structure. ${ }^{12,13}$ Therefore, the utilization of MOFs can be a pioneering key for the field of photocatalytic $\mathrm{H}_{2}$ generation. ${ }^{14-16}$ A MOF-based photocatalytic system can consist of several components in addition to the MOF, which is the main component and usually acts as an antenna harvesting light. Upon illumination, the MOF generates charge-carriers (electrons and holes) with the electrons being responsible to reduce $\mathrm{H}_{2} \mathrm{O}$ into $\mathrm{H}_{2}$. In addition to the MOF photocatalyst, the photocatalytic system (for $\mathrm{H}_{2}$ generation) usually comprises: $i$. a co-catalyst that can attract the photogenerated electrons; $i$. a photosensitizer that may be used to extend the light absorption into the visible region, when a UV-light-active (MOF) photocatalyst is used $;{ }^{17}$ iii. a sacrificial agent that is usually employed as an electron donor to scavenge the photogenerated holes; and $i v$. a redox shuttle which can expedite the charge transfer between the photocatalyst and the co-catalyst. ${ }^{18}$

Several MOF-based photocatalytic systems have been tested for visible-light driven $\mathrm{H}_{2}$ production; most of them are based on reductive metal ions such as $\mathrm{Ti}^{\mathrm{IV}}$ and $\mathrm{Zr}^{\mathrm{IV}}$ and visiblelight-active ligands that can harvest solar light and convert it into $\mathrm{H}_{2}$ (Tables 1 and S2). ${ }^{17-29}$ Recently, $\mathrm{Cu}^{\mathrm{I}}$ or $\mathrm{Cu}^{\mathrm{II}}$-based MOFs were found to be good candidates to photocatalytically reduce $\mathrm{H}_{2} \mathrm{O}$ into for $\mathrm{H}_{2}$ under UV/vis or visible irradiation (Table S2). ${ }^{30-32}$ Despite the high promise of MOFs towards water splitting, the majority of these MOF-based systems demonstrate very low apparent quantum yields or still utilize expensive noble-metal co-catalysts such as $\mathrm{Pt}$ nanoparticles (NPs). ${ }^{18,20}$ The latter is due to the easy preparation and intrinsic activity of Pt NPs, yet their use does not guarantee the best photocatalytic performance. Although very few examples have been reported in the literature, the synergy between MOFs and co-catalysts is proven to be a key factor for the photocatalytic performance of the system, as different hydrogen generation rates and quantum yields are observed when the same MOF is used (Tables 1). Consequently, there is a need to investigate the activity of alternative co-catalysts and identify photocatalytic systems and conditions optimum for water splitting and hydrogen generation.

Table 1: Comparison of the visible-light driven photocatalytic performance of systems utilizing MIL-125-NH $\mathrm{Na}_{2}$ the photocatalyst with different co-catalysts.

\begin{tabular}{cccccc} 
Co-catalyst & $\begin{array}{c}\text { Light } \\
\text { Source } \lambda \\
(\mathrm{nm})\end{array}$ & $\begin{array}{c}\text { HER } \\
(\mu \mathrm{mo} \\
1 \mathrm{~h}^{-1} \\
\left.\mathrm{~g}^{-1}\right)\end{array}$ & $\begin{array}{c}\text { Apparent } \\
\text { Quantum } \\
\text { Yield }(\%)\end{array}$ & $\begin{array}{c}\text { Stability } \\
(\mathrm{h})\end{array}$ & Ref. \\
\hline Pt NPs & $\geq 420$ & $* 333$ & - & $>9$ & 15 \\
Pt NPs & $\geq 420$ & $* 525$ & - & $>9$ & 16 \\
$\mathrm{Co}^{\mathrm{II}}$ complex & $\geq 380$ & 553 & - & $>7.5$ & 17 \\
Co ${ }^{\text {III }}$ & $\geq 408$ & $* 637$ & 0.5 & $>70$ & 18 \\
oxime & & & & & \\
$\mathbf{N i}_{2} \mathbf{P}$ NPs & $\geq \mathbf{4 2 0}$ & $\mathbf{8 9 4}$ & $\mathbf{6 . 6 - 4 5 0 n m}$ & $>\mathbf{8 4}$ & This \\
& & & $\mathbf{2 7 . 0 - 4 0 0 n m}$ & & work \\
\hline
\end{tabular}

HERP: $_{2}$ evolution rate with respect to the photocatalyst

* Calculated based on reported data

Herein, we report a photocatalytic system consisting of the visible-light absorbing MIL-125$\mathrm{NH}_{2}$ as the photocatalyst and the $\mathrm{Ni}_{2} \mathrm{P}$ nanoparticles (NPs) as the co-catalyst. Although both materials have been tested with other photocatalysts or co-catalysts, ${ }^{23,33}$ our $\mathrm{Ni}_{2} \mathrm{P} / \mathrm{MIL}-125-\mathrm{NH}_{2}$ system exhibits $\mathrm{H}_{2}$ evolution rates and apparent quantum yields (AQY) under visible-light 
irradiation, that are among the highest values reported to date for MOFs. The $\mathrm{H}_{2}$ generation rate produced by $\mathrm{Ni}_{2} \mathrm{P} / \mathrm{MIL}-125-\mathrm{NH}_{2}$ is almost 3 times higher than the Pt/MIL-125-NH system tested under the same reaction conditions, suggesting that the selection of the co-catalyst is crucial for the design of efficient photocatalytic systems. In addition, $\mathrm{Ni}_{2} \mathrm{P} / \mathrm{MIL}-125-\mathrm{NH}_{2}$ outperforms $\mathrm{Ni}_{2} \mathrm{P} / \mathrm{TiO}_{2}$, with $\mathrm{TiO}_{2}$ being the most well studied photocatalyst for water splitting, ${ }^{34}$ highlighting the exceptional synergy between MIL-125- $\mathrm{NH}_{2}$ and $\mathrm{Ni}_{2} \mathrm{P}$.

MIL-125- $\mathrm{NH}_{2}$ and $\mathrm{Ni}_{2} \mathrm{P}$ NPs were synthesized and characterized according to reported procedures (Sections S1-S7). ${ }^{23,35}$ The size of the NPs is around 16-19 $\mathrm{nm}$ as shown by Transmission Electron Microscopy (TEM) images, and the $\mathrm{N}_{2}$ isotherm collected at $77 \mathrm{~K}$ revealed a BET surface area of 27.8 $\mathrm{m}^{2} / \mathrm{g}$ (Fig. S2-S5). In order to assess the performance and optimize the composition of our photocatalytic system toward $\mathrm{H}_{2}$ generation, different combinations of MIL-125- $\mathrm{NH}_{2}$ and $\mathrm{Ni}_{2} \mathrm{P}$ powders were mixed in a reactor containing a solvent mixture of acetonitrile $\left(\mathrm{CH}_{3} \mathrm{CN}\right)$, triethylamine (TEA) as the sacrificial agent, and water. The reactor was then irradiated with visible light by a $300 \mathrm{~W}$ Xe lamp using a longpass cut-off filter allowing $\lambda \geq 420 \mathrm{~nm}$, and the generated $\mathrm{H}_{2}$ was analysed by gas chromatography. As shown in Fig. S7 and S8, when increasing amounts of $\mathrm{Ni}_{2} \mathrm{P}$ were added to a constant amount of MIL125- $\mathrm{NH}_{2}$, the $\mathrm{H}_{2}$ evolution rate increases since the co-catalyst attracts the electrons efficiently, inhibiting the undesired charge carrier recombination. By reaching $9.2( \pm 0.4)$ wt $\%$ of $\mathrm{Ni}_{2} \mathrm{P}$, the $\mathrm{H}_{2}$ evolution rate is maximized. At this ratio, there is an optimum level of interactions between $\mathrm{Ni}_{2} \mathrm{P}$ and MIL-125- $\mathrm{NH}_{2}$, promoting the electron transfer to the $\mathrm{Ni}_{2} \mathrm{P}$. Further increasing the amount of $\mathrm{Ni}_{2} \mathrm{P}$ leads to a decrease in the $\mathrm{H}_{2}$ production rate, as the interaction between MIL-125- $\mathrm{NH}_{2}$ and the $\mathrm{Ni}_{2} \mathrm{P}$ is already at its maximum, while the $\mathrm{Ni}_{2} \mathrm{P}$ NPs simultaneously compete with MIL-125- $\mathrm{NH}_{2}$ in light absorption, shielding-effect. ${ }^{36}$ As displayed in Fig. $\mathrm{S} 9$, the $\mathrm{Ni}_{2} \mathrm{P} / \mathrm{MIL}-125-\mathrm{NH}_{2}$ system exhibits a highly enhanced activity that is almost 300 times higher than that of the pristine MIL-125- $\mathrm{NH}_{2}\left(2.249 \mu \mathrm{mol} \mathrm{h}^{-1} \mathrm{~g}^{-1}\right)$, reaching a $\mathrm{H}_{2}$ evolution rate of $648 \mu \mathrm{mol} \mathrm{h} \mathrm{h}^{-1} \mathrm{~g}^{-1}$ and $7865 \mu \mathrm{mol} \mathrm{h} \mathrm{h}^{-1} \mathrm{~g}^{-1}$ with respect to MIL-125- $\mathrm{NH}_{2}$ and $\mathrm{Ni}_{2} \mathrm{P}$. Blank photocatalytic experiments (under visible-light irradiation) using solely $\mathrm{Ni}_{2} \mathrm{P}$ with and without the $\mathrm{NH}_{2}-$ $\mathrm{H}_{2} \mathrm{BDC}$ (amino-terephthalic acid) ligand resulted in no $\mathrm{H}_{2}$ generation, confirming the unique advantage of having MIL-125- $\mathrm{NH}_{2}$ as a photocatalyst within the system. Moreover, recycling experiments for the optimum ratio between $\mathrm{Ni}_{2} \mathrm{P}$ and MIL-125- $\mathrm{NH}_{2}$ revealed that the $\mathrm{H}_{2}$ evolution rate of this system remains stable for at least seven catalytic runs (each for $12 \mathrm{~h}$, Fig. S10). The PXRD patterns of the samples before and after photocatalysis are comparable, confirming that the crystallinity of both MIL$125-\mathrm{NH}_{2}$ and $\mathrm{Ni}_{2} \mathrm{P}$ is retained after $84 \mathrm{~h}$ of continuous irradiation (Fig. S10).

We further examined the performance of $\mathrm{Ni}_{2} \mathrm{P} / \mathrm{MIL}-125-\mathrm{NH}_{2}$ by varying the solvent mixtures; we kept the same ratio of acetonitrile and TEA, whereas the $\mathrm{H}_{2} \mathrm{O}$ content was varied from $1.63 \mathrm{v} / \mathrm{v} \%$ to 8.19 $\mathrm{v} / \mathrm{v} \%$ ( $\mathrm{V}_{\text {total }}$ was kept constant) (Fig. 1a and S11). By increasing the water content, the $\mathrm{H}_{2}$ evolution rate also increases. With the optimum photocatalytic solution of $4.87 \mathrm{v} / \mathrm{v} \%$ water, the photocatalytic system reached a $\mathrm{H}_{2}$ evolution rate of $894 \mu \mathrm{mol} \mathrm{h}^{-1} \mathrm{~g}^{-1}$ and $10134 \mu \mathrm{mol} \mathrm{h}^{-1} \mathrm{~g}^{-1}$ with respect to the MIL125- $\mathrm{NH}_{2}$ and $\mathrm{Ni}_{2} \mathrm{P}$. To the best of our knowledge, this is among the highest $\mathrm{H}_{2}$ evolution rate for a visible-light active photocatalytic-MOF system reported to date (Table 1). ${ }^{19,20,23}$. The AQYs of the optimum system at 400 and $450 \mathrm{~nm}$ were calculated by Ferrioxalate actinometry ${ }^{37,38}$ and reached values of 27.0 and $6.6 \%$, respectively (Section S9). These are the highest reported efficiencies for MOFs ${ }^{18,23,39}$ (Tables 1 and S2) and comparable to leading photocatalysts..$^{40,41}$

In order to compare our photocatalytic $\mathrm{MOF}$ system with $\mathrm{TiO}_{2}$, we investigated the parallel photocatalytic performance of $\mathrm{Ni}_{2} \mathrm{P} / \mathrm{MIL}-125-\mathrm{NH}_{2}$ and $\mathrm{Ni}_{2} \mathrm{P} / \mathrm{TiO}$ toward $\mathrm{H}_{2}$ generation, under irradiations that include UV light since $\mathrm{TiO}_{2}$ is characterized by an overly large optical band gap $(\sim 3$ $\mathrm{eV})$ and operates only under UV irradiation. Commercial $\mathrm{TiO}_{2}(\mathrm{P} 25$, Degausa - which is a standard material in the field of $\mathrm{TiO}_{2}$-photocatalyzed reactions) was used ${ }^{42}$ and the amount of $\mathrm{Ni}_{2} \mathrm{P}$ added was 
first varied in order to determine the optimum system. In order to compare our photocatalytic MOF system with $\mathrm{TiO}_{2}$, we investigated the parallel photocatalytic performance of $\mathrm{Ni}_{2} \mathrm{P} / \mathrm{MIL}-125-\mathrm{NH}_{2}$ and $\mathrm{Ni}_{2} \mathrm{P} / \mathrm{TiO}_{2}$ toward $\mathrm{H}_{2}$ generation, under irradiations that include $\mathrm{UV}$ light since $\mathrm{TiO}_{2}$ is characterized by an overly large optical band gap $(\sim 3 \mathrm{eV})$ and operates only under UV irradiation. The optimum $\mathrm{Ni}_{2} \mathrm{P} / \mathrm{TiO}_{2}$ system contains $15.3( \pm 0.4)$ wt $\%$ of $\mathrm{Ni}_{2} \mathrm{P}$ (Section $\mathrm{S} 10$ ). The best performing $\mathrm{Ni}_{2} \mathrm{P} / \mathrm{MIL}-125-$ $\mathrm{NH}_{2}$ and $\mathrm{Ni}_{2} \mathrm{P} / \mathrm{TiO}_{2}$ systems generated $\mathrm{H}_{2}$ with a rate of 3878 and $1708 \mu$ mols g ${ }^{-1} \mathrm{~h}^{-1}$, with respect to the MIL-125- $\mathrm{NH}_{2}$ and $\mathrm{TiO}_{2}$, and the AQY for $\mathrm{Ni}_{2} \mathrm{P} / \mathrm{TiO}_{2}$ at $400 \mathrm{~nm}$ was found to be $0.9 \%$ (Fig. $1 \mathrm{~b}$ and Section S9). It is apparent that by a simple subtraction of the visible-light-driven $\mathrm{H}_{2}$ evolution rate previously obtained $\left(894 \mu \mathrm{mol} \mathrm{h}^{-1} \mathrm{~g}^{-1}\right), \mathrm{Ni}_{2} \mathrm{P} / \mathrm{MIL}-125-\mathrm{NH}_{2}$ outperforms $\mathrm{Ni}_{2} \mathrm{P} / \mathrm{TiO}_{2}$ even in the UV light region. This can be attributed to the high porosity of MIL-125- $\mathrm{NH}_{2}$ (BET: $1197.5 \mathrm{~m}^{2} / \mathrm{g}$ ) that allows for easy light penetration compared to the solid $\mathrm{TiO}_{2}$, the high molar absorptivity of MIL-125- $\mathrm{NH}_{2}$, and particularly the exceptional synergy between MIL-125- $\mathrm{NH}_{2}$ and $\mathrm{Ni}_{2} \mathrm{P}$.
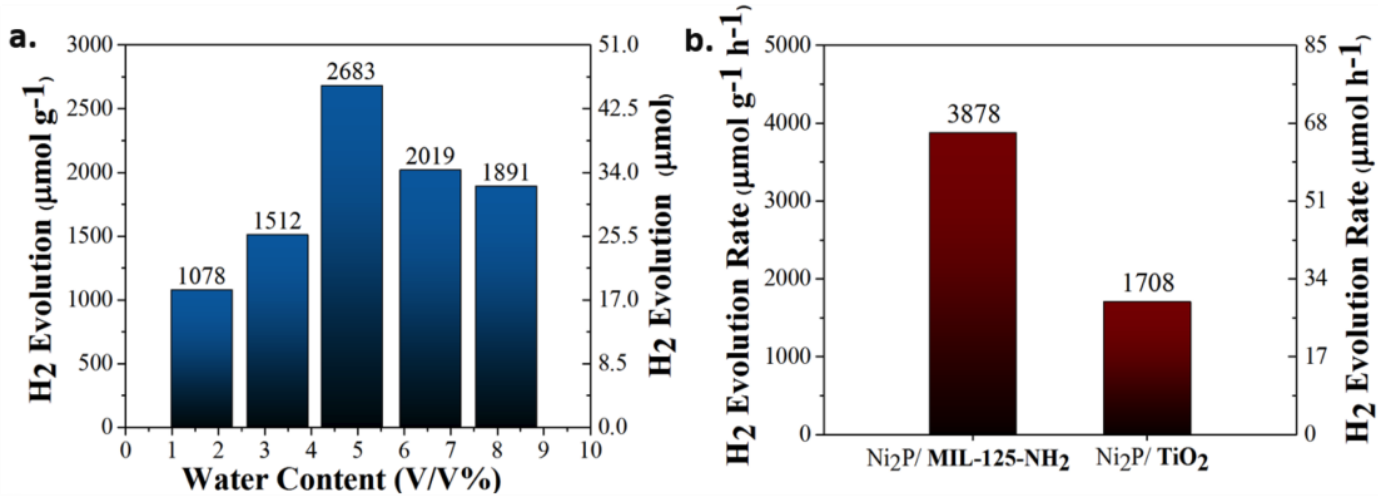

Fig. 1 (a) $\mathrm{H}_{2}$ evolution of the optimum $\mathrm{Ni}_{2} \mathrm{P} / \mathrm{MIL}-125-\mathrm{NH}_{2}$ system with different water contents under visiblelight irradiation for 3 hours and (b) Maximum $\mathrm{H}_{2}$ evolution rates of $9.2( \pm 0.4) \mathrm{wt} \% \mathrm{Ni}_{2} \mathrm{P} / \mathrm{MIL}-125-\mathrm{NH}_{2}$ and $15.3( \pm 0.4) \mathrm{wt} \% \mathrm{Ni}_{2} \mathrm{P} / \mathrm{TiO}_{2}$ with respect to the photocatalyst under $\mathrm{UV} / \mathrm{vis}$ light irradiation for 3 hours.

As indicated in previous studies, the $\mathrm{NH}_{2}-\mathrm{BDC}$ within MIL-125- $\mathrm{NH}_{2}$ acts as an antenna that absorbs light and promotes an electron from the Highest Occupied Crystalline Orbitals (HOCOs) to the Lowest Unoccupied Crystalline Orbitals (LUCOs) of MIL-125- $\mathrm{NH}_{2}$. The HOCOs comprise mainly the $\pi$ orbitals of the ligand while the LUCOs have contributions from the $\mathrm{O} 2 \mathrm{p}$ and the Ti $3 \mathrm{~d}$ orbitals. ${ }^{43,44} \mathrm{As}$ proposed by Santaclara et al., upon illumination, electron-hole pairs are generated, with the holes mainly localized and restricted in movement in the $-\mathrm{NH}_{2}$ groups of the ligand, whereas the electrons are relatively free to migrate to the $\mathrm{Ti} 3 \mathrm{~d}$ orbitals (confirmed by the presence of $\mathrm{Ti}^{3+}$ in the electron paramagnetic resonance (EPR) spectrum of MIL-125- $\mathrm{NH}_{2}$ shown in Fig. 2), thus allowing effective charge separation. ${ }^{42,45}$ Such charge separation provides an efficient stabilization of the photoexcited species; a key element for allowing the electrons to reach the surface of MIL-125- $\mathrm{NH}_{2}$, before their recombination with the holes.

In order to further understand the localization of the charge-carriers, our density functional theory (DFT) calculations showed that after injection of a single hole and a single electron, the hole is localized in the $\pi$ orbital of $\mathrm{NH}_{2}$-BDC whereas the electron is not only localized on the Ti $3 \mathrm{~d}$ orbitals but also delocalized along the $\mathrm{NH}_{2}$-BDC ligand. The delocalized states of electrons ensure their efficient transfer to the surface of MIL-125- $\mathrm{NH}_{2}$ (Section S11). Subsequently, in our photocatalytic system, the photo-excited electron is transferred from the LUCOs of MIL-125- $\mathrm{NH}_{2}$ to $\mathrm{Ni}_{2} \mathrm{P}$, as evidenced by the presence of $\mathrm{Ni}^{+}$ in the EPR spectrum of $\mathrm{Ni}_{2} \mathrm{P} / \mathrm{MIL}-125-\mathrm{NH}_{2}$ (Fig. 2 and Section S12), and then to the protons. Inductively couple plasma optical emission spectrometry (ICP-OES) studies (Section S13) and SEM mapping images of the $\mathrm{Ni}_{2} \mathrm{P} / \mathrm{MIL}-125-\mathrm{NH}_{2}$ (Fig. S12, S13) reveal that $90 \%$ of $\mathrm{Ni}_{2} \mathrm{P}$ NPs are attached and evenly distributed on the external surface of MIL-125- $\mathrm{NH}_{2}$ crystals suggesting that efficient electron transfer 
can occur. In terms of thermodynamics of electron transfer, from the energy diagram (Fig. S22), the conduction band of $\mathrm{Ni}_{2} \mathrm{P}$ has a lower reduction potential $\left(\mathrm{E}_{\mathrm{vac}}=-4.50 \mathrm{eV}\right)^{46}$ than the LUCOs of MIL$125-\mathrm{NH}_{2}\left(\mathrm{E}_{\mathrm{vac}}=-3.80 \mathrm{eV}\right)$, and is in the same level as the reduction potential of $\mathrm{H}^{+} / \mathrm{H}_{2}\left(\mathrm{E}_{\mathrm{vac}}=-4.50 \mathrm{eV}\right.$, $\left.\mathrm{E}_{\mathrm{NHE}}=0 \mathrm{eV}\right) .{ }^{43}$ This large negative energy difference between MIL-125- $\mathrm{NH}_{2}$ and $\mathrm{Ni}_{2} \mathrm{P}$ stems from the discrete $\mathrm{Ti}_{8} \mathrm{O}_{8}$ cluster on MIL-125- $\mathrm{NH}_{2}$ being exceptionally reducing. This contrasts with $\mathrm{TiO}_{2}$ in which the extended structure conduction band is at the lower reduction potential of $-4.25 \mathrm{eV}$, compared to the discrete cluster. Consequently, in $\mathrm{TiO}_{2}$, the lower reduction potential negates the reductive power of $\mathrm{TiO}_{2}$ compared to MIL-125- $\mathrm{NH}_{2}$, and therefore, decreases the effectiveness of the electron transfer to the $\mathrm{Ni}_{2} \mathrm{P} .{ }^{47}$ The smaller thermodynamic driving force confirms the lower performance of $\mathrm{Ni}_{2} \mathrm{P} / \mathrm{TiO}_{2}$.

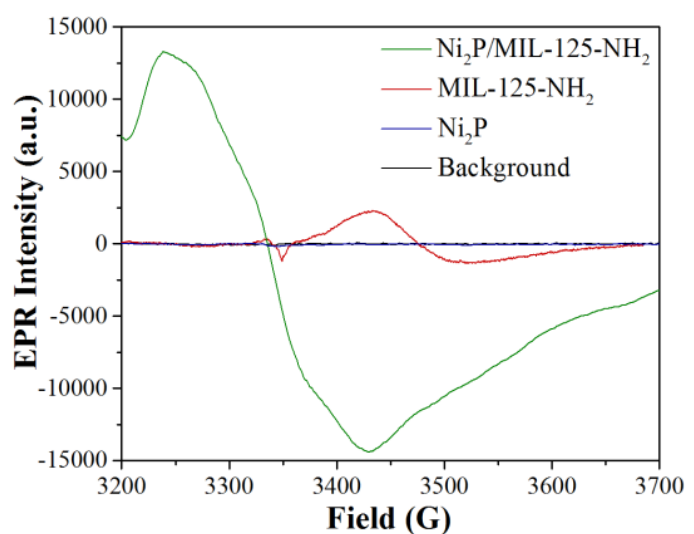

Fig. 2 EPR spectra of $9.2( \pm 0.4) \mathrm{wt} \% \mathrm{Ni}_{2} \mathrm{P} / \mathrm{MIL}-125-\mathrm{NH}_{2}$ (green), MIL-125- $\mathrm{NH}_{2}$ (red), $\mathrm{Ni}_{2} \mathrm{P}($ blue) after visible light irradiation.

Insights into the catalytic activity of $\mathrm{Ni}_{2} \mathrm{P}$ can be obtained by comparing $\mathrm{Ni}_{2} \mathrm{P} / \mathrm{MIL}-125-\mathrm{NH}_{2}$ with other systems. Nasalevich et al. reported a system containing cobaloxime complexes encapsulated within the pores of MIL-125- $\mathrm{NH}_{2}$ in MeCN/TEA/ $\mathrm{H}_{2} \mathrm{O}$ mixture. This system produces $\mathrm{H}_{2}$ with a maximum rate of $637 \mu \mathrm{mol} \mathrm{g}^{-1} \mathrm{~h}^{-1}$. Since the cobaloxime complex $\left(E_{\text {vac }}=-4.25 \mathrm{eV}\right)$ has a higher reduction potential than that of $\mathrm{Ni}_{2} \mathrm{P}$ (but lower than the LUCOs of MIL-125-NH ), the energy difference is less, which is a key reason for its inferior performance compared to $\mathrm{Ni}_{2} \mathrm{P} / \mathrm{MIL}-125-\mathrm{NH}_{2}$ (Fig. S23). ${ }^{23}$ Matsuoka et al. reported that the Pt/MIL-125- $\mathrm{NH}_{2}$ system in $0.01 \mathrm{M}$ aqueous TEOA solution displays a maximum $\mathrm{H}_{2}$ evolution rate of $525 \mu \mathrm{mol} \mathrm{g} \mathrm{g} \mathrm{h}^{-1}{ }^{20}$ Upon testing $\mathrm{Ni}_{2} \mathrm{P} / \mathrm{MIL}-125-\mathrm{NH}_{2}$ in $0.01 \mathrm{M}$ TEOA aqueous solution, we observed that the photocatalytic solution darkened and the MIL-125- $\mathrm{NH}_{2}$ degraded and dissolved (Section S14.1).

In order to compare the performance of $\mathrm{Ni}_{2} \mathrm{P} / \mathrm{MIL}-125-\mathrm{NH}_{2}$ with Pt/MIL-125- $\mathrm{NH}_{2}$, we synthesized "naked" Pt NPs ${ }^{48}$ with the size of $\sim 19 \mathrm{~nm}$ (Fig. S28, S29). We then mixed them with MIL-125-NH 2 and investigated the performance of this system using the same conditions used for $\mathrm{Ni}_{2} \mathrm{P} / \mathrm{MIL}-125-\mathrm{NH}_{2}$. The $\mathrm{Pt} / \mathrm{MIL}-125-\mathrm{NH}_{2}$ produced $\mathrm{H}_{2}$ with a maximum evolution rate of $269 \mu \mathrm{mol} \mathrm{g}^{-1} \mathrm{~h}^{-1}$ (Fig. S30). Based on the energy diagram shown in Fig. S23, Pt might have higher driving force compared to $\mathrm{Ni}_{2} \mathrm{P}$ for attracting the photogenerated electrons from the MOF; however, not all electrons transferred from MIL125- $\mathrm{NH}_{2}$ to $\mathrm{Pt}$ have enough energy for the reduction of protons from $\mathrm{H}^{+}$to $\mathrm{H}_{2}$. In addition, photochemical chronoamperometry measurements (Fig. 3a, S33, S34) showed that upon illumination both $\mathrm{Ni}_{2} \mathrm{P} / \mathrm{MIL}-125-\mathrm{NH}_{2}$ and Pt/MIL-125- $\mathrm{NH}_{2}$ exhibit comparable initial photocurrents at the early stage, but the photocurrent in the presence of Pt NPs decays faster over time. This suggests the faster charge recombination in Pt/MIL-125- $\mathrm{NH}_{2}$ compared to $\mathrm{Ni}_{2} \mathrm{P} / \mathrm{MIL}-125-\mathrm{NH}_{2}$, inhibiting thus its $\mathrm{H}_{2}$ production performance. 
The effectiveness of charge separation in the $\mathrm{Ni}_{2} \mathrm{P} / \mathrm{MIL}-125-\mathrm{NH}_{2}$ and Pt/MIL-125- $\mathrm{NH}_{2}$ was further studied by photoluminescence (PL) emission spectroscopy (Fig. 3b and S33). The suspension of MIL$125-\mathrm{NH}_{2}$ exhibits fluorescence with the maximum peak centered at $\sim 560 \mathrm{~nm}$ when excited at $420 \mathrm{~nm}$. The addition of the co-catalysts ( $\mathrm{Pt}$ and $\mathrm{Ni}_{2} \mathrm{P}$ NPs) diminishes the PL emission, indicating the electron transfer from MIL-125- $\mathrm{NH}_{2}$ to the co-catalysts and depopulating the excited electrons in MIL-125- $\mathrm{NH}_{2}$. However, in the case of $\mathrm{Ni}_{2} \mathrm{P} / \mathrm{MIL}-125-\mathrm{NH}_{2}$, the quenching of the photoluminescence is more drastic and when the amount of $\mathrm{Ni}_{2} \mathrm{P}$ reaches $9.2( \pm 0.4)$ wt\% (optimum amount), the mixture $\mathrm{Ni}_{2} \mathrm{P} / \mathrm{MIL}-125$ $\mathrm{NH}_{2}$ shows no detectable photoluminescence emission, illustrating the key role of these NPs in attracting the electrons and thus eliminating the electron-hole recombination. On the other hand, the addition of the $2.0( \pm 0.4)$ wt\% amount of Pt (optimized Pt/MIL-125- $\mathrm{NH}_{2}$ system), does not induce complete quenching of the PL emission. Lifetime measurements of MIL-125- $\mathrm{NH}_{2}$, and the optimized Pt/ MIL$125-\mathrm{NH}_{2}$ and $\mathrm{Ni}_{2} \mathrm{P} / \mathrm{MIL}-125-\mathrm{NH}_{2}$ systems revealed that the latter has shorter lifetime compared to the others (Fig. 3c), confirming the more efficient electron transfer from MIL-125- $\mathrm{NH}_{2}$ to $\mathrm{Ni}_{2} \mathrm{P}$.

a.

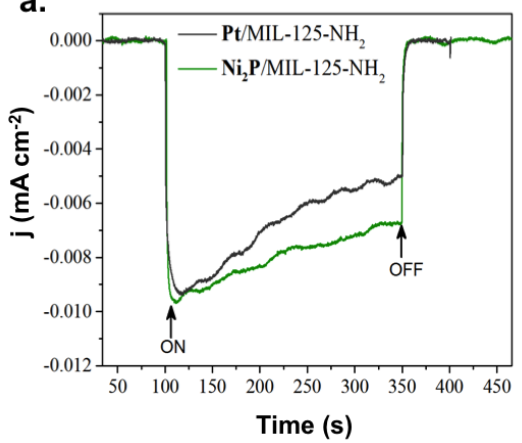

b.

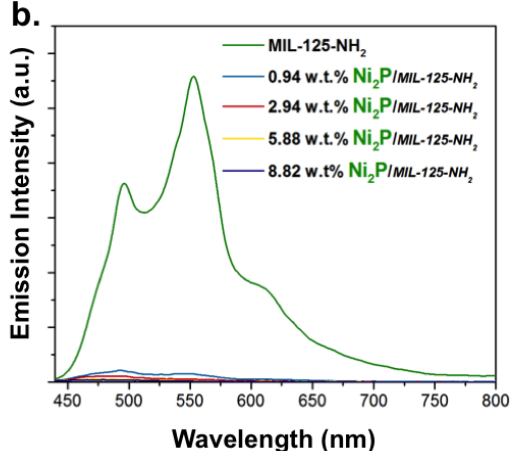

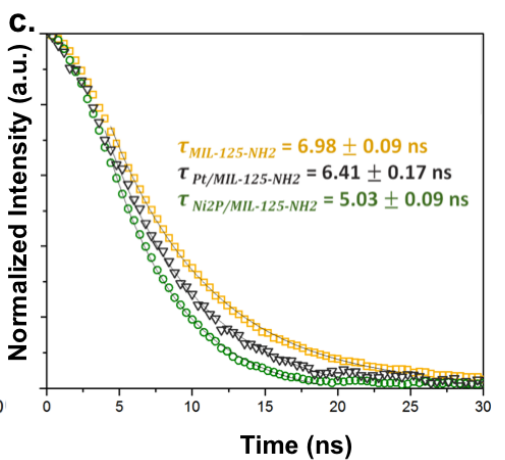

Fig. 3 (a) Photocurrent responses of MIL-125- $\mathrm{NH}_{2}$ with the optimized amounts of co-catalysts $\left(\mathrm{Ni}_{2} \mathrm{P}\right.$ green and Pt black), (b) PL spectra (excited at $420 \mathrm{~nm}$ ) for the suspensions of MIL-125- $\mathrm{NH}_{2}$ with different amounts of $\mathrm{Ni}_{2} \mathrm{P}$ and (c) Time Resolved PL decay curves of MIL-125- $\mathrm{NH}_{2}$ (yellow squares), Pt/MIL-125- $\mathrm{NH}_{2}$ (grey triangles) and $\mathrm{Ni}_{2} \mathrm{P} / \mathrm{MIL}-125-\mathrm{NH}_{2}$ (green circles). The excitation wavelength was $420 \mathrm{~nm}$.

While it is not straightforward to compare the catalytic activity of $\mathrm{Pt}$ and $\mathrm{Ni}_{2} \mathrm{P}$, it is apparent that a good co-catalyst should be able to trap protons, transfer electrons, bond the hydrogen atoms, and desorb the $\mathrm{H}_{2}$ molecules formed. $\mathrm{Ni}_{2} \mathrm{P}$ NPs, with the presence of both Ni and P sites on their surface of the NPs acting as hydride and proton-acceptor centers exhibit particularly good behaviour for $\mathrm{H}_{2}$ generation when combined with MIL-125- $\mathrm{NH}_{2}{ }^{49}{ }^{50}$ These results highlight the impact of the co-catalyst in enhancing the performance of a photocatalytic MOF based system. ${ }^{51}$

\section{Conclusions}

In conclusion, we report a low-cost, stable, and easily prepared (based on mixing) photocatalytic system consisting of MIL-125- $\mathrm{NH}_{2}$ and $\mathrm{Ni}_{2} \mathrm{P}$ NPs that exhibits remarkable $\mathrm{H}_{2}$ generation. The system appreciably outperforms $\mathrm{Ni}_{2} \mathrm{P} / \mathrm{TiO}_{2}$ under UV irradiation and other visible-light active MOF systems, while maintaining its integrity for a long time. The absorptivity in the visible region, the charge separation in MIL-125- $\mathrm{NH}_{2}$, the efficient electron transport to the external surface of MIL-125- $\mathrm{NH}_{2}$ via a delocalized state, the efficient attraction of electrons by the $\mathrm{Ni}_{2} \mathrm{P}$ NPs (compared to Pt NPs) and the inherent nature of $\mathrm{Ni}_{2} \mathrm{P}$ to catalyze the $\mathrm{H}_{2}$ generation are the key factors for the significantly enhanced photocatalytic activity of this system. With high apparent quantum yields under visible-light irradiation and easy scale-up synthesis of both MIL-125- $\mathrm{NH}_{2}$ and $\mathrm{Ni}_{2} \mathrm{P}$ NPs, this photocatalytic system brings itself a step closer to practical 'solar-driven' applications. 


\section{Conflicts of interest}

KCS, BS, SK, CPI, TNN and EPFL have filed a patent application (EP17180055.0) that relates to visible-light active Ti-MOFs and cheap co-catalysts for photocatalytic water splitting and hydrogen generation.

\section{Author Contribution}

SK, TNN, CPI, BV and FME have performed and analysed all experiments described in the manuscript. GC, DO, AM and BS have performed the computational studies and analysed the data. NGC and KS have carried out the photocurrent experiments and AS and LF have designed, performed and analysed the EPR experiments. KCS led the project and KCS, SK, TNN and CPI wrote the article with contributions from all co-authors.

\section{Acknowledgements}

SK, TNN and KCS thank Swiss National Science Foundation (SNF) for funding under the Ambizione Energy Grant n.PZENP2_166888. CPI is grateful to the EU for a Marie Curie Fellowship (705861 ASPAir, H2020-MSCA-IF-2015). GC is supported by the National Center of Competence in Research (NCCR), Materials' Revolution: Computational Design and Dis-covery of Novel Materials (MARVEL), of the Swiss National Science Foundation (SNSF). The research of DO is supported by the European Research Council (ERC) under the European Union's Horizon 2020 research and innovation program (Grant Agreement No. 666983, MaGic). AM thanks the Swedish Research Council (VR) for funding.

\section{Notes and references}

(1) Ramachandran, R.; Menon, R. K. International Journal of Hydrogen Energy 1998, 23, 593.

(2) Schoedel, A.; Ji, Z.; Yaghi, O. M. Nat Energy 2016, 1.

(3) Chaubey, R.; Sahu, S.; James, O. O.; Maity, S. RENEW. SUST. ENERG. REV. 2013, 23, 443.

(4) Lewis, N. S.; Nocera, D. G. Proceedings of the National Academy of Sciences 2006, 103, 15729 .

(5) Osterloh, F. E. Chem. Mater. 2008, 20, 35.

(6) Mills, A.; Le Hunte, S. J. Photochem. Photobiol. A 1997, 108, 1.

(7) Gao, W.-Z.; Xu, Y.; Chen, Y.; Fu, W.-F. Chem. Commun. 2015, 51, 13217.

(8) Sun, Z.; Zheng, H.; Li, J.; Du, P. Energy \& Environmental Science 2015, 8, 2668.

(9) Rowsell, J. L. C.; Yaghi, O. M. Microporous and Mesoporous Materials 2004, 73, 3.

(10) Li, B.; Wen, H.-M.; Cui, Y.; Zhou, W.; Qian, G.; Chen, B. Advanced Materials 2016, 28, 8819 .

(11) Nelson, A. P.; Farha, O. K.; Mulfort, K. L.; Hupp, J. T. Journal of the American Chemical Society 2009, 131, 458.

(12) Wang, S.; Wang, X. Small 2015, 11, 3097.

(13) Yu, X. C., Seth M. J. Am. Chem. Soc. 2016,, 138, 12320.

(14) Zhang, T.; Lin, W. Chem. Soc. Rev. 2014, 43, 5982.

(15) Wang, J.-L.; Wang, C.; Lin, W. ACS Catalysis 2012, 2, 2630.

(16) Pullen, S.; Ott, S. Topics in Catalysis 2016, 59, 1712.

(17) He, J.; Wang, J.; Chen, Y.; Zhang, J.; Duan, D.; Wang, Y.; Yan, Z. Chemical Communications 2014, 50, 7063.

(18) Fateeva, A.; Chater, P. A.; Ireland, C. P.; Tahir, A. A.; Khimyak, Y. Z.; Wiper, P. V.; Darwent, J. R.; Rosseinsky, M. J. Angew. Chem. Int. Ed. 2012, 51, 7440. 
(19) Meyer, K.; Bashir, S.; Llorca, J.; Idriss, H.; Ranocchiari, M.; van Bokhoven, J. A. Chem. Eur. J. 2016, 22, 13894.

(20) Horiuchi, Y.; Toyao, T.; Saito, M.; Mochizuki, K.; Iwata, M.; Higashimura, H.; Anpo, M.; Matsuoka, M. J. Phys. Chem. C 2012, 116, 20848.

(21) Toyao, T.; Saito, M.; Horiuchi, Y.; Mochizuki, K.; Iwata, M.; Higashimura, H.; Matsuoka, M. Catal. Sci. Technol. 2013, 3, 2092.

(22) Wang, D.; Song, Y.; Cai, J.; Wu, L.; Li, Z. New Journal of Chemistry 2016, 40, 9170.

(23) Nasalevich, M. A.; Becker, R.; Ramos-Fernandez, E. V.; Castellanos, S.; Veber, S. L.; Fedin, M. V.; Kapteijn, F.; Reek, J. N. H.; van der Vlugt, J. I.; Gascon, J. Energy Environ. Sci. 2015, 8, 364.

(24) Gomes Silva, C.; Luz, I.; Llabrés i Xamena, F. X.; Corma, A.; García, H. Chem. Eur. J. 2010, $16,11133$.

(25) Wang, C.; deKrafft, K. E.; Lin, W. J. Am. Chem. Soc. 2012, 134, 7211.

(26) Zhou, J.-J.; Wang, R.; Liu, X.-L.; Peng, F.-M.; Li, C.-H.; Teng, F.; Yuan, Y.-P. Appl. Surf. Sci. 2015, 346, 278.

(27) Xiao, J.-D.; Shang, Q.; Xiong, Y.; Zhang, Q.; Luo, Y.; Yu, S.-H.; Jiang, H.-L. Angew. Chem. 2016, $128,9535$.

(28) Toyao, T.; Saito, M.; Dohshi, S.; Mochizuki, K.; Iwata, M.; Higashimura, H.; Horiuchi, Y.; Matsuoka, M. Chem. Commun. 2014, 50, 6779.

(29) Sun, X.; Yu, Q.; Zhang, F.; Wei, J.; Yang, P. Catalysis Science \& Technology 2016, 6, 3840.

(30) Shi, D.; Zheng, R.; Sun, M.-J.; Cao, X.; Sun, C.-X.; Cui, C.-J.; Liu, C.-S.; Zhao, J.; Du, M. Angewandte Chemie International Edition 2017, 56, 14637.

(31) Wu, Z.-L.; Wang, C.-H.; Zhao, B.; Dong, J.; Lu, F.; Wang, W.-H.; Wang, W.-C.; Wu, G.-J.; Cui, J.-Z.; Cheng, P. Angewandte Chemie International Edition 2016, 55, 4938.

(32) Dong, X.-Y.; Zhang, M.; Pei, R.-B.; Wang, Q.; Wei, D.-H.; Zang, S.-Q.; Fan, Y.-T.; Mak, T. C. W. Angew. Chem. Int. Ed. 2016, 55, 2073.

(33) Cao, S.; Chen, Y.; Wang, C.-J.; He, P.; Fu, W.-F. Chemical Communications 2014, 50, 10427.

(34) Ohno, T.; Sarukawa, K.; Tokieda, K.; Matsumura, M. J. Catal. 2001, $203,82$.

(35) Kumar, D. P.; Choi, J.; Hong, S.; Reddy, D. A.; Lee, S.; Kim, T. K. ACS Sustain. Chem. Eng. 2016, $4,7158$.

(36) Ran, J.; Zhang, J.; Yu, J.; Jaroniec, M.; Qiao, S. Z. Chem. Soc. Rev. 2014, 43, 7787.

(37) Kuhn, H. B., S.; Schmidt, R. Pure and Applied Chemistry 2004, 76., 2105.

(38) Hatchard, C. P., C. A. In Proceedings of the Royal Society of London A: Mathematical, Physical and Engineering Sciences; The Royal Society: 1956 1956, 235, 518.

(39) Shen, L.; Luo, M.; Liu, Y.; Liang, R.; Jing, F.; Wu, L. Applied Catalysis B: Environmental 2015, 166, 445 .

(40) Maeda, K.; Teramura, K.; Lu, D.; Takata, T.; Saito, N.; Inoue, Y.; Domen, K. Nature 2006, 440, 295.

(41) Chen, X.; Shen, S.; Guo, L.; Mao, S. S. Chem. Rev. 2010, 110, 6503.

(42) Nasalevich, M. A.; Hendon, C. H.; Santaclara, J. G.; Svane, K.; van der Linden, B.; Veber, S. L.; Fedin, M. V.; Houtepen, A. J.; van der Veen, M. A.; Kapteijn, F.; Walsh, A.; Gascon, J. 2016, 6, 23676.

(43) Hendon, C. H.; Tiana, D.; Fontecave, M.; Sanchez, C.; D’arras, L.; Sassoye, C.; Rozes, L.; Mellot-Draznieks, C.; Walsh, A. J. Am. Chem. Soc. 2013, 135, 10942.

(44) Walsh, A.; Catlow, C. R. A. ChemPhysChem 2010, 11, 2341.

(45) Santaclara, J. G.; Nasalevich, M. A.; Castellanos, S.; Evers, W. H.; Spoor, F. C. M.; Rock, K.; Siebbeles, L. D. A.; Kapteijn, F.; Grozema, F.; Houtepen, A.; Gascon, J.; Hunger, J.; van der Veen, M. A. Chem. Sus. Chem. 2016, 9, 388.

(46) Sharon, M.; Tamizhmani, G.; Levy-Clement, C.; Rioux, J. Solar Cells 1989, 26, 303. 
(47) Xu, Y.; Schoonen, M. A. A. American Mineralogist 2000, 85, 543.

(48) Zhang, B.; Xue, Y.; Sun, H.; Jiang, A.; Li, Z.; Hao, J. RSC Advances 2016, 6, 56083.

(49) Zou, X.; Zhang, Y. Chem. Soc. Rev. 2015, 44, 5148.

(50) Liu, P.; Rodriguez, J. A. Journal of the American Chemical Society 2005, 127, 14871.

(51) Chen, Y.; Qin, Z. Catalysis Science \& Technology 2016, 6, 8212. 